\title{
TRANSFERENCIAS GUBERNAMENTALES E INVERSIÓN EN CAPITAL EN MUNICIPIOS PERUANOS: EL CASO DE LAS RENTAS POR RECURSOS NATURALES*
}

\author{
Recibido: 04 de abril de 2016 • Aprobado: 05 de agosto de 2016 \\ DOI: DOI: 10.22395/seec.v19n41a3 \\ Luis Sánchez Alcalde
}

\section{RESUMEN}

El objetivo de este artículo es evaluar el comportamiento del gasto de capital frente a las transferencias por recursos naturales en los municipios peruanos. El análisis tomó información de ingresos y gastos del Registro Nacional de Municipalidades del Perú registrado por el Instituto Nacional de Estadística e Informática para el año 2014. Se estimó una función lineal del gasto de capital aplicando el método de mínimos cuadrados ordinarios para los 1838 municipios. Los resultados muestran que la inversión en capital en los municipios del Perú responde mejor a las transferencias por recursos naturales en comparación con cualquier otro tipo de ingresos; sin embargo, se evidencia que un mayor nivel de transferencias no repercute en un mayor nivel de inversión en capital humano.

\section{PALABRAS CLAVE}

Inversión en capital de los municipios, transferencias, recursos naturales, municipalidades, Perú

\section{CLASIFICACIÓN JEL}

$\mathrm{H} 54, \mathrm{H} 72$

\section{CONTENIDO}

Introducción; 1. Revisión de literatura y evidencia empírica; 2.Estructura de transferencias y gastos municipales en Perú; 3. Anàlisis de datos y resultados; 4. Conclusiones; Bibliografía.

\footnotetext{
Este artículo de investigación es producto de la tesis de Licenciatura en Economía del autor, titulada: "Transferencias gubernamentales y sus efectos en el gasto de inversión municipal en la región Ancash", contó con la asesoría de la Dra. (c) Silvia Pérez Huamán, y fue sustentada el 24 de abril del 2014 en las instalaciones de la Universidad Nacional Agraria La Molina, Lima, Perú.

** Economista, Universidad Nacional Agraria La Molina, Lima, Perú. Profesor, Facultad de Economía y Planificación, Universidad Nacional Agraria La Molina, Lima, Perú. Estudiante de posgrado en Estudios Sociales en la Universidad Autónoma Metropolitana, Ciudad de México, México. Dirección: Calle Sur 23. №164A. Colonia Leyes de Reforma, Delegación Iztapalapa, México. Correo electrónico: luissanchez@ lamolina.edu.pe.
} 


\section{GOVERNMENT TRANSFERS AND CAPITAL INVESTMENTS IN PERUVIAN MUNICIPALITIES: THE CASE OF PROFITS GENERATED FROM NATURAL RESOURCES}

\section{RESUMEN}

The objective of this article is to evaluate the behavior of capital expense concerning the resource transfers for natural resources within the Peruvian municipalities. The analysis was based on income and expense information fron the National Municipality Records of Peru, recorded by the National Statistics and Informatics Center for 2014. A linear function was estimated for capital expense applying the ordinary minimum square method for the 1838 municipalities. Results show that the capital investments within the Peruvian municipalities is more focused on natural resource transfers when compared to any other type of income; nevertheless, it is also evidenced that a higher level of transfers doesn't generate in higher investment levels in human capital.

\section{KEY WORDS}

Capital investment in municipalities, transfers, natural resources, municipalities, Peru.

\section{JEL CLASSIFICATION}

$\mathrm{H} 54, \mathrm{H} 72$

\section{CONTENT}

Introduction; 1 . Literature review and empiric evidence; 2 . Expense and transfer structure in the Peruvian municipalities; 3. Data analysis and results; 4. Conclusions; Bibliography.

\section{TRANSFERÊNCIAS GOVERNAMENTAIS E INVESTIMENTO EM CAPITAL EM MUNICÍPIOS PERUANOS: 0 CASO DAS RENDAS POR RECURSOS NATURAIS}

\section{RESUMO}

O objetivo deste artigo é avaliar o comportamento do gasto de capital frente às transferências por recursos naturais nos municípios peruanos. A análise tomou informação de ingressos e gastos do Registro Nacional de Municipalidades do Peru. Registrado pelo Instituto Nacional de Estatística e Informática para o ano 2014. Se estimou uma função lineal do gasto de capital aplicando o método de mínimos quadrados ordinários para os 1838 municípios. Os resultados mostram que o investimento em capital nos municípios do Peru responde melhor às transferências por recursos naturais em comparação a qualquer outro tipo de ingressos; embora, se evidência que um maior nível de transferências não repercute num maior nível de investimento em capital humano.

\section{PALAVRAS CHAVE}

Investimento em capital dos municípios, transferências, recursos naturais, municipalidades, Peru.

\section{CLASSIFICAÇÃO JEL} $\mathrm{H} 54, \mathrm{H} 72$

\section{CONTEÚDO}

Introdução; 1. Revisão de literatura e evidência empírica; 2.Estrutura de transferências e gastos municipais em Peru; 3. Análise de dados e resultados; 4. Conclusões; Bibliografia. 


\section{INTRODUCCIÓN}

Durante los últimos 10 años, 2005-2015, en Perú se ha producido un incremento considerable de recursos financieros transferidos a los gobiernos municipales, cuya fuente principal proviene de los impuestos derivados de la extracción y explotación de los recursos naturales tanto renovables como no renovables; todo esto en el contexto del proceso de descentralización fiscal que se dio a inicios de la década de los años 2000 con la promulgación de la Ley 27783, Ley de Bases de Descentralización (CRP, 2002). Sin embargo, este incremento de transferencias ha sido respaldado principalmente por procesos sostenidos de crecimiento del sector minero (recursos no renovables), que pone de manifiesto un aspecto sensible, ya que la economía peruana, como muchas de Latinoamérica, es altamente dependiente de las materias primas, lo que ha generado que se mantenga la constante de una economía con un modelo primario exportador.

Ante esta importante fuente de ingresos municipales, la tarea fundamental de los gobiernos locales es hacer el adecuado gasto de capital que el marco legal nacional les exige, establecido en la Ley 27506, Ley del Canon (CRP, 2001). Según Trujillo (2008), este gasto debe ejecutarse en pro de una verdadera descentralización de responsabilidades fiscales, invirtiendo en gasto de capital en áreas de educación, salud, saneamiento, cultura, entre otros gastos que permitan el desarrollo económico local. Por lo tanto, el problema radica en conocer si los municipios del Perú están ejecutando un adecuado gasto de capital, bajo el marco legal existente y bajo la política de una asignación eficiente de los recursos. Las preguntas que se plantearon para el desarrollo de la investigación son: ¿Cuál es el efecto de un aumento en las transferencias por recursos naturales sobre gasto de capital de los gobiernos municipales?, y ¿̇uál es el tipo de gasto de capital en donde los gobiernos municipales han invertido más recursos?

Desde el enfoque normativo, la descentralización es el proceso de transferencia de obligaciones y funciones de parte del Gobierno Central hacia los municipios. En ese sentido es el Gobierno Central quien tiene la función de ofrecer bienes y servicios a la población; sin embargo, y de acuerdo con Parodi (2005), muchas veces esta función no se realiza de manera adecuada ya que el Gobierno Central se encuentra lejos de las necesidades urgentes de la población; por tal motivo se plantea que son los municipios quienes deben asumir este rol, es decir, cumplir la función de asignación del Estado.

En este contexto, es necesario saber de dónde provendrán los ingresos para satisfacer las necesidades de la población. Siguiendo a Piffano (2005), los municipios pueden usar sus ingresos propios, pero también pueden financiarlos con los recursos transferidos del Gobierno Central. Sin embargo, como plantean Hines y 
Thaler (1995), esta última forma de financiamiento ha generado efectos anómalos que han producido ineficiencia en el esfuerzo por generar rentas propias. En el caso de las transferencias por recursos naturales, estas son bastante significativas y, de acuerdo con Gylfason y Zoega (2001), han generado una dependencia negativa y un alto costo de oportunidad al renunciar a la disponibilidad del recurso y a su agotamiento.

El objetivo de este trabajo es analizar la relación cuantitativa y cualitativa entre el gasto de capital y las transferencias gubernamentales para todos los municipios del Perú, con base en la última información disponible del Registro Nacional de Municipalidades 2014. Para lograr dicho objetivo, se hizo un análisis per-cápita de las distintas transferencias que podrían estar correlacionadas con el gasto de capital, estimando diferentes modelos econométricos según la cantidad de transferencia por recursos naturales que los municipios reciben. La base de datos está integrada por la información de ingresos y gastos ejecutados por los 1838 municipios del Perú. Asimismo, se analizaron los distintos tipos de gasto de capital en que los municipios deben ejecutar su presupuesto.

Los resultados mostraron que desde el punto de vista cuantitativo existe una relación lineal positiva y significativa entre las transferencias por recursos naturales y la inversión en capital, siendo mayor en aquellos municipios que pertenecen a regiones donde las transferencias per-capita son altas (por encima del promedio nacional). Por otro lado, el gasto de capital en salud y educación más significativo se encontró en aquellos municipios que pertenecen a regiones donde las transferencias por recursos naturales se consideraron bajas (por debajo del promedio nacional).

Esta sección corresponde a la introducción del artículo, posteriormente se presenta la sección 1, donde se realiza la revisión de literatura y evidencia empírica; luego en la sección 2, se presenta la estructura de transferencias y gastos municipales en Perú. En la sección 3, se hace el análisis de datos y resultados; y en la sección 4, finalmente, se explican las conclusiones del trabajo. El documento finaliza con la presentación de la bibliografía.

\section{REVISIÓN DE LITERATURA Y EVIDENCIA EMPÍRICA}

\subsection{Los enfoques del federalismo fiscal}

A partir 1950, la teoría económica ha respaldado cada vez más la descentralización a través de las contribuciones del hoy llamado federalismo fiscal. Esta teoría busca justificar normativamente la descentralización y, a su vez, establecer criterios de eficiencia económica para este proceso. El concepto de eficiencia en esta teoría implica que las decisiones del Estado sobre el uso de recursos y producción de 
bienes y servicios públicos tomen en cuenta las preferencias de los individuos. Wiesner (1994) indica que el federalismo fiscal tiene que ver básicamente con la capacidad de los gobiernos -y de sus distintos niveles- para utilizar eficientemente los recursos públicos puestos a su disposición. De esta eficiencia va a depender, en gran medida, el crecimiento a largo plazo de los países y la calidad de vida de la mayoría de los habitantes.

El enfoque normativo tiene como su máximo exponente a Richard Musgrave que, según Trujillo (2008), plantea que las funciones básicas del Estado son la descentralización, la estabilización y la asignación. Estas funciones se justifican porque existen fallas de mercado, bienes públicos, desigualdad en la distribución de la renta, monopolios, externalidades y bajo crecimiento, entre otros, razones que justifican la intervención del Estado para tratar de mejorar las condiciones de funcionamiento de las economías. La teoría indica que el interrogante sobre estas funciones radica en conocer cuál debería ser transferida a otros niveles de gobierno.

En ese sentido, es el Gobierno Central quien tiene la función de ofrecer bienes y servicios a la población; sin embargo, muchas veces esta función no se realiza de manera adecuada ya que este se encuentra lejos de las necesidades urgentes de la población; por tal motivo, y de acuerdo con Parodi (2005), se plantea que son los gobiernos locales quienes deben asumir este rol, es decir, la función de asignación es aquella que debe transferirse. Ahora bien, si los gobiernos locales tienen dicha función, el interrogante es: ¿cómo pueden financiar su gasto, con recursos propios o transferencias provenientes del Gobierno Central? Según Piffano (2005) un ordenamiento de los esquemas de coordinación financiera, según el grado de autonomía reconocido a los gobiernos, podría adoptar algunos de los siguientes sistemas:

\section{- Sistemas tributarios propios}

Con bases y alícuotas bajo control local que pueden asumir las formas de separación de fuentes o de concurrencia de fuentes de ambos niveles de Gobierno.

\section{- Alícuotas adicionales}

Las bases y alícuotas (nacionales) son establecidas por el Gobierno Central, admitiendo el establecimiento de alícuotas adicionales por parte de los gobiernos locales.

\section{- Participación o coparticipación impositiva}

Es un sistema de centralización de la recaudación y distribución del producto entre los distintos niveles de Gobierno (bases y alícuotas establecidas en el 
ámbito nacional). Las participaciones están preestablecidas en instrumentos legales. Existe libertad en cada nivel de Gobierno sobre las decisiones de gasto.

\section{- Transferencias de libre disponibilidad}

El Gobierno Central transfiere fondos, generalmente a través de su presupuesto, fijando el monto global y la participación de cada unidad local (usualmente con criterio redistributivo), pero estas determinan el destino de los fondos (gastos a financiar).

\section{- Transferencias condicionadas}

Tanto el monto de la transferencia como el destino (tipo de gasto a financiar) de los fondos es determinado por el Gobierno Central.

La elección del sistema o combinación de sistemas dependerá del peso que se asigne a los argumentos de eficiencia y equidad, junto con otros objetivos de política, los que varían según sea el enfoque empleado en el análisis y las circunstancias sociopolíticas de cada país. En el contexto de los países de Latinoamérica, se debe tener en cuenta que la recaudación tributaria de un nivel de gobierno puede ser insuficiente para financiar el total de sus gastos, en cuyo caso la diferencia debe ser financiada con transferencias de otros niveles de gobierno. En este sentido, las transferencias deben cumplir con dos grandes objetivos: (i) la búsqueda de la eficiencia y (ii) la equidad inter-jurisdiccional. De acuerdo con Wiesner (1994), la dificultad principal radica en asegurar que el diseño y administración de las transferencias no opere en contradicción con las tres funciones principales del Gobierno Central.

El enfoque normativo ha planteado que al momento de transferir recursos es necesario establecer unos criterios que permitan conocer si los desequilibrios que se pretenden corregir son el producto de muy baja capacidad económica y administrativa o si responden a muy bajo esfuerzo y desempeño fiscal local. Esto con el objetivo de evitar efectos adversos o contrarios a los que en principio se persiguen: la eficiencia, la equidad y la estabilidad que promuevan el desarrollo y crecimiento de las naciones. Como plantea Piffano (2005), la teoría normativa ha elaborado reglas sobre la estructuración de los aportes gubernamentales, distinguiéndose dos grandes tipos de transferencias lo condicionados y los no condicionados.

\section{- Aportes no condicionados o block grants}

Son aquellos de tipo general, es decir, de libre asignación por parte del receptor, cuya justificación reside en cuestiones de equidad. Son transferencias de 
nivelación o igualación, dirigidas a los municipios más pobres que presentan grandes carencias en los servicios sociales o bases tributarias muy débiles, con el propósito de cumplir con el objetivo de redistribución del ingreso en la sociedad. Los aportes no condicionados pretenden redistribuir el ingreso de las regiones ricas a las regiones pobres de un país.

\section{- Aportes condicionados o categorical grants}

Son transferencias específicas que el Gobierno Central debe asignar para el financiamiento de programas que involucran beneficios a los municipios. Este tipo de aportes se justifica con el argumento de subsidiar a los individuos cuyas actividades generan externalidades positivas, pues esto induce a internalizar los beneficios producidos a terceros, y de esta misma forma el Gobierno local tendrá en cuenta los beneficios generados a residentes de otras jurisdicciones dentro del cálculo de su decisión. Si lo que se busca es incrementar la disponibilidad de una categoría concreta de un bien público, como educación y salud, los aportes condicionados son más idóneos que los aportes generales o no específicos.

Dentro de los aportes condicionados, se encuentran también los aportes con contrapartida (matching grants), los cuales actúan como un incentivo para el Gobierno local y se justifican en el principio de escasez de los recursos y por la necesidad de utilizarlos donde se maximice su rendimiento. De acuerdo con Wiesner (1994), los aportes con contrapartida tienen dos objetivos: primero, buscan un esfuerzo fiscal propio, y segundo, hacer más transparentes las cuentas presupuestal horizontal y vertical. De esta forma, las transferencias tendrán un efecto multiplicador sobre el ahorro y la inversión pública y contribuirán al desarrollo institucional y político de los gobiernos locales; es decir, se busca evitar que las transferencias actúen como impuestos negativos, al inducir a la pereza fiscal en las jurisdicciones.

Por otra parte, Piffano (2005) indica que los aportes no condicionados a los gobiernos locales son equivalentes a transferencias de ingreso; por lo tanto, el incremento del gasto público local dependerá de la elasticidad ingreso que este tenga para la comunidad local (es decir, se producirá un efecto ingreso), mientras que los aportes condicionados estimularán un mayor gasto público local, y se producirá no solo un efecto ingreso, sino también un efecto precio al reducirse el costo marginal de los incrementos en el gasto local; en este caso, los cambios en el gasto están sujetos a la elasticidad precio correspondiente.

En Perú existen transferencias condicionadas y no condicionadas, y para este trabajo se han incluido ambas. Por ejemplo, el canon, EL sobrecanon y las regalías 
se encuentran en la clasificación de transferencias condicionadas, ya que existe un marco legal establecido sobre la ejecución de su gasto (Ley del Canon, Ley 27506; CRP, 2001). Por el contrario, el Fondo de Compensación Municipal (FONCOMUN) representa una transferencia no condicionada, ya que los gobiernos locales del Perú, hoy en día, pueden hacer uso libre en su ejecución para suplir tanto gastos corrientes como de capital.

Por último, el federalismo fiscal tiene el otro enfoque, el positivo, que ha estudiado con frecuencia el efecto que tienen las transferencias sobre el gasto público de los gobiernos locales, teniendo como base la escuela del pensamiento Public Choice, cuya premisa general indica que el Gobierno Central es el ente que debe ser limitado o reducido por el bienestar de la sociedad. La escuela del Public Choice explica que la descentralización de potestades fiscales inducirá a una mayor responsabilidad fiscal por parte de los distintos niveles de Gobierno, al punto que sean los mismos gobiernos locales quienes fijen sus propios impuestos y de esta manera se facilite la "imputabilidad" de las decisiones fiscales.

De acuerdo con Piffano (2005) dicha imputabilidad se refiere, estrictamente, a que el Gobierno local es responsable de su gasto en función de los impuestos que se generen en su jurisdicción. Sin embargo, se producen ciertos efectos anómalos, pues el gasto y la generación de ingresos en el sector público es distinto al que sucede en el sector privado; en el mercado privado cuando un agente adquiere bienes y servicios involucra la decisión simultánea de desprenderse de sus ingresos para así financiar la producción de bienes que adquirió. Pero de acuerdo con Trujillo (2008), en el sector público no existe tal simultaneidad, pues los ingresos que se generen (tributos, impuestos) para solventar los gastos públicos tienen un proceso distinto y pueden provenir de otras jurisdicciones u otros niveles de gobierno, es decir, en el sector público existe una relación débil entre la decisión de gasto público y decisiones sobre tributación; esto genera la llamada "ilusión fiscal" que hacen los políticos al fundamentar su gasto sobre recursos que no, necesariamente, provendrán de los impuestos que se generen en su jurisdicción.

Este fenómeno ha sido analizado con detalle en el trabajo de Hines y Thaler (1995), que dieron a conocer que las transferencias podrían ocasionar efectos de pereza fiscal, es decir, efectos anómalos que comprometerían la eficiencia de la burocracia estatal. En síntesis, se demostró que cuando ocurre un incremento en las transferencias, se genera un aumento del gasto público local mayor que si se hubiese experimentado un aumento equivalente de los ingresos propios del Gobierno local, es decir, se crea un efecto sustitución donde el Gobierno local busca maximizar su presupuesto, mas no el bienestar de la población. Este efecto se conoce como 
flypaper, que para los federalistas significa el principal aporte negativo que tienen las transferencias sobre la eficiencia del gasto público.

Para el caso peruano, las características del enfoque positivo del federalismo fiscal pueden comprobarse si se analiza el efecto de las transferencias (no condicionadas) sobre el gasto de capital, en contraposición a los ingresos propios (impuestos, alcabalas, ingresos extraordinarios por ventas, entre otros). En este caso, dicho gasto debería responder mejor ante un incremento de los impuestos generados en la jurisdicción del Gobierno local, que ante un incremento del FONCOMUN, por ejemplo.

\subsection{El gasto público y sus efectos en el crecimiento económico}

Existe una abundante literatura sobre el gasto público y su efecto en el crecimiento económico. Por ejemplo, Barro (1990) encontró una relación positiva entre inversión pública y el crecimiento del Producto Bruto Interno (PBI) de varios países desarrollados; más adelante Kneller, Bleaney y Gemmell (1990) contribuyeron con su análisis sobre los efectos de los impuestos sobre el gasto público y el crecimiento a largo plazo. Asimismo, Glaeser, Scheinkman, y Shleifer (1995) examinaron cómo las experiencias de crecimiento de las 203 principales ciudades de Estados Unidos estuvieron relacionadas con el tamaño y naturaleza del Gobierno, entre otras variables.

En el particular, con respecto a la inversión pública en capital, Devarajan, Swaroop y Zou (1996) llegaron a la conclusión de que en los países en desarrollo los gobiernos tienen el gasto público deficiente en favor del gasto de capital, en comparación con los gastos corrientes. Años más tarde, Gregoriou y Ghosh (2009) lograron captar el impacto en el crecimiento heterogéneo de capital público y gasto corriente para 15 países en desarrollo, y concluyeron que los países con importantes inversiones en activos públicos tienen fuertes efectos negativos sobre el crecimiento. Sin embargo, a pesar de estos resultados de los países en desarrollo, Beuren y Rodrigues (2014), demostraron que aquellos países cuyo gasto de capital fue significativo, en particular en salud y educación, obtuvieron como resultado tasas de crecimiento medias más altas. Entre este grupo de países destacaron Ecuador, Colombia y Perú, que durante el período 2000-2010 obtuvieron tasas de crecimiento significativas.

Durante las últimas décadas, se ha dado importancia al estudio del gasto público de capital en el aspecto del capital humano. Esto ha tenido fundamento en los nuevos modelos de crecimiento, como el modelo de crecimiento endógeno planteado por Romer (1994), donde la variable capital se expresó en un sentido más amplio, incluyendo el capital humano, es decir, el PBI no solo dependería de capital físico como las máquinas, sino de aquel valor agregado que ofrece la fuerza labo- 
ral, como la innovación, conocimiento y habilidades, variables que hoy en día son consideradas importantes en el crecimiento económico de un país. Bajo los nuevos modelos de crecimiento, el capital debe entenderse no solo como la inversión en bienes físicos, sino considerar al capital humano. De La Fuente (2003) indica que el capital humano es un concepto amplio y multidimensional y debe entenderse como los conocimientos y habilidades de los trabajadores. De La Fuente (2003) argumenta que los nuevos conocimientos resultarán útiles en la producción de bienes, servicios y, además, nuevos conocimientos que conllevarán a un mejor nivel de ingresos y un ritmo más elevado de crecimiento de la productividad.

Por el lado empírico, el efecto del gasto público en capital humano sobre el crecimiento y desarrollo económico en Latinoamérica ha dado resultados interesantes, como lo explica Neira (2007) quien demostró el importante impacto positivo que el capital humano tiene sobre el desarrollo económico a través del efecto inversión. Neira (2007) concluye que los países que alcanzaron los máximos niveles de educación en la década de 1990 son también los que han tenido un puesto más destacado en su nivel de desarrollo económico, incluso en circunstancias de escasa dotación de recursos naturales en proporción a su territorio y/o a su población. Sin embargo, el trabajo de Giménez (2005) pone de manifiesto que la dotación de capital humano en Latinoamérica se encuentra en una situación de atraso en comparación con otras partes del mundo y, aunque en su estudio se indica que de forma intrarregional se ha experimentado un proceso de convergencia, es necesario que este proceso continúe y alcance a los países desarrollados.

Para el caso peruano, según el glosario de presupuesto público del Ministerio de Economía y Finanzas (MEF, 2006), la inversión pública en capital se entiende como "aquel gasto que busca aumentar el activo del sector público y sirve de instrumento para la producción de bienes y servicios". En este sentido, la inversión en capital municipal supondrá el aumento de los activos para la producción de bienes y servicios que puedan satisfacer la demanda local. De esto se debe desprender que la inversión de capital representa una variable sensible en el proceso de descentralización fiscal peruano. En el ámbito municipal, la inversión en capital también considera la inversión en capital humano, como salud y educación, y esto se considera como funciones orgánicas del Gobierno municipal.

\section{ESTRUCTURA DE TRANSFERENCIAS Y GASTOS MUNICIPALES EN PERÚ}

En el Perú existen 1838 municipios distribuidos en las 25 regiones político-administrativas del país. Cada municipio tiene su propia gobernación y debe cumplir con la función de asignación de recursos para la satisfacción de las necesidades 
de sus ciudadanos. Para realizar sus funciones, estos ejecutan diversos tipos de ingresos y gastos. Las transferencias gubernamentales son el tipo de ingresos más importantes que forman parte de la estructura financiera de los municipios; el total de las transferencias está compuesto por el canon, el sobrecanon y las regalías, el FONCOMUN y el rubro otras transferencias.

De acuerdo con el MEF (2006), el canon es un ingreso que les corresponde a los gobiernos municipales por poseer dentro del espacio geográfico de su jurisdicción recursos naturales como minerales, hidrocarburos, recursos forestales, pesqueros e hidroenergéticos. Las municipalidades en donde se explotan dichos recursos reciben canon todos los años, ya que su procedencia se deriva del impuesto a la renta de las empresas que explotan recursos naturales; y en algunos casos reciben sobrecanon y regalías.

Según el último Registro Nacional de Municipalidades (RENAMU) elaborado por el Instituto Nacional de Estadística e Informática (INE), para el año 2014, las transferencias por canon, sobrecanon y regalías sumaron un total de USD 2.156 millones ${ }^{2}$, que representó el 47,7 \% del total de las transferencias nacionales. Gran parte de este monto le pertenece al sector minero, y en una clasificación más amplia, a aquellas rentas generadas por recursos no renovables. Cabe precisar que el canon procedente de este tipo de recursos representó el 96 \% del canon total para el año 2014.

Respecto a las transferencias por recursos naturales, su uso se ampara en la Ley Gubernamental 27506, donde se indica que estas deben ser usadas solo para ejecutar gasto de capital. De acuerdo con el artículo 4 de la Ley 28077 (CRP, 2003), "los recursos que los gobiernos regionales y gobiernos locales reciban por concepto de canon serán utilizados exclusivamente para el financiamiento o cofinanciamiento de proyectos u obras de infraestructura de impacto regional y local, respectivamente, a cuyo efecto establecen una cuenta destinada a esta finalidad...". Es decir, en términos generales, la ley exige que las transferencias por recursos naturales sean gastadas en capital que derive en la generación de capital humano.

Como se explica en la introducción, más del 90 \% de las transferencias por recursos naturales en el Perú proviene de los recursos no renovables. Al respecto,

\footnotetext{
1 El canon, sobrecanon y regalías difieren entre sí tanto por el monto transferido como por la base imponible. El canon siempre representa un monto, el sobrecanon solo se paga en el caso de la actividad petrolera y las regalías son solo del tipo mineras y gasíferas, que representan una contraprestación económica que las empresas extractivas pagan por el derecho de usufructo de la zona intervenida.

2 Se utilizó un tipo de cambio promedio referencial de S/. 3,00 por USD 1,00 estimado por la Superintendencia Nacional de Administración Tributaria (SUNAT).
} 
en las regiones de Loreto, Apurímac, Ayacucho, Madre de Dios, Huánuco, Ucayali, Lambayeque, Cusco y San Martín, más del 99 \% de sus transferencias por recursos naturales provienen de los no renovables. Por el contrario, en la región Callao el 99 $\%$ de las transferencias proviene de recursos renovables; en Huancavelica, el 89,8 $\%$, y en Amazonas, el 88,1 \%. Esta última es la región que menos transferencias per cápita por recursos naturales recibió (USD 0,007). En el gráfico 1 se muestra la distribución de las transferencias por recursos renovables y no renovables para las 25 regiones del Perú.

Gráfico 1. Transferencias per cápita por regiones y tipo de recursos naturales

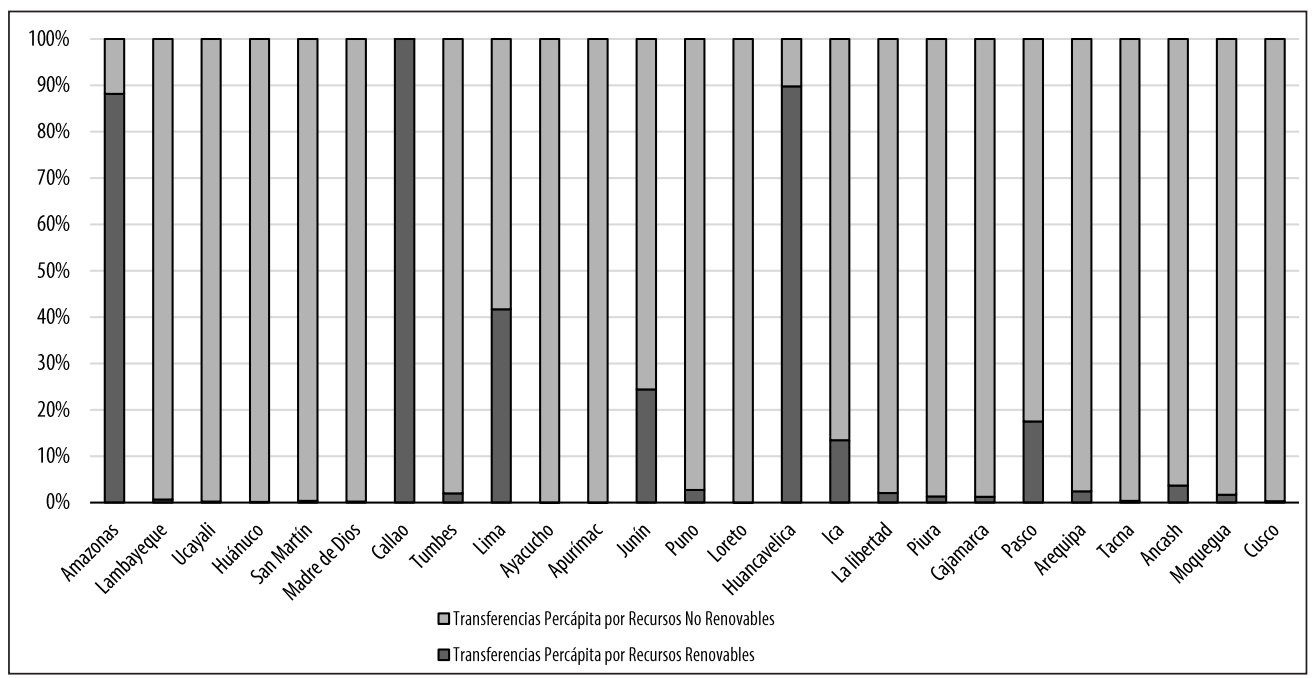

Fuente: elaboración del autor a partir de la información de RENAMU-INEI (2014)

De esto se desprende que para el caso peruano, existe una gran dependencia de generación de recursos financieros de la explotación del capital natural, particularmente de recursos no renovables. Según Tello (2005), de esto podría desprenderse la aplicación de la teoría de la "maldición de los recursos naturales" para el caso de las finanzas municipales del Perú. Esta "maldición" se refiere a la dependencia que los municipios tienen por los recursos naturales, como la extracción minera, y el retraso sobre el desarrollo local debido a los efectos no significativos sobre el empleo en sectores como la manufactura o los servicios. A pesar de que las actividades extractivas tienen el encadenamiento de otras actividades económicas, estas están sujetas a una sola actividad, que al momento de cesar, afectara las demás actividades económicas. Esto puede significar que las rentas generadas por los recursos naturales provocan un efecto de pereza y no diversificación o innovación por parte de la población y los gobiernos municipales. Tello (2005) expone que economías 
con mayor dotación de recursos naturales también tienen una menor dotación y/o grado de generación de capital humano, mayor desigualdad de ingresos, instituciones más débiles, y menores niveles de inversión.

Por otro lado, el FONCOMUN es una transferencia que reciben todas las municipalidades del Perú, independientemente de la dotación de los recursos naturales que albergan en su jurisdicción. Según la Ley 27630 (CRP, 2001), el FONCOMUN representa una transferencia No Condicionada dado que el Concejo Municipal fija la utilización de dichos recursos en porcentajes para gasto corriente e inversiones, determinando los niveles de responsabilidad correspondientes (Ley del Financiamiento Municipal, 2002).

Según la última información del INEI, para el año 2014, las transferencias totales representaron el 51 \% del total de ingresos municipales. En el gráfico 2 se muestra la distribución de estas.

Gráfico 2. Distribución de las transferencias gubernamentales en Perú, 2014

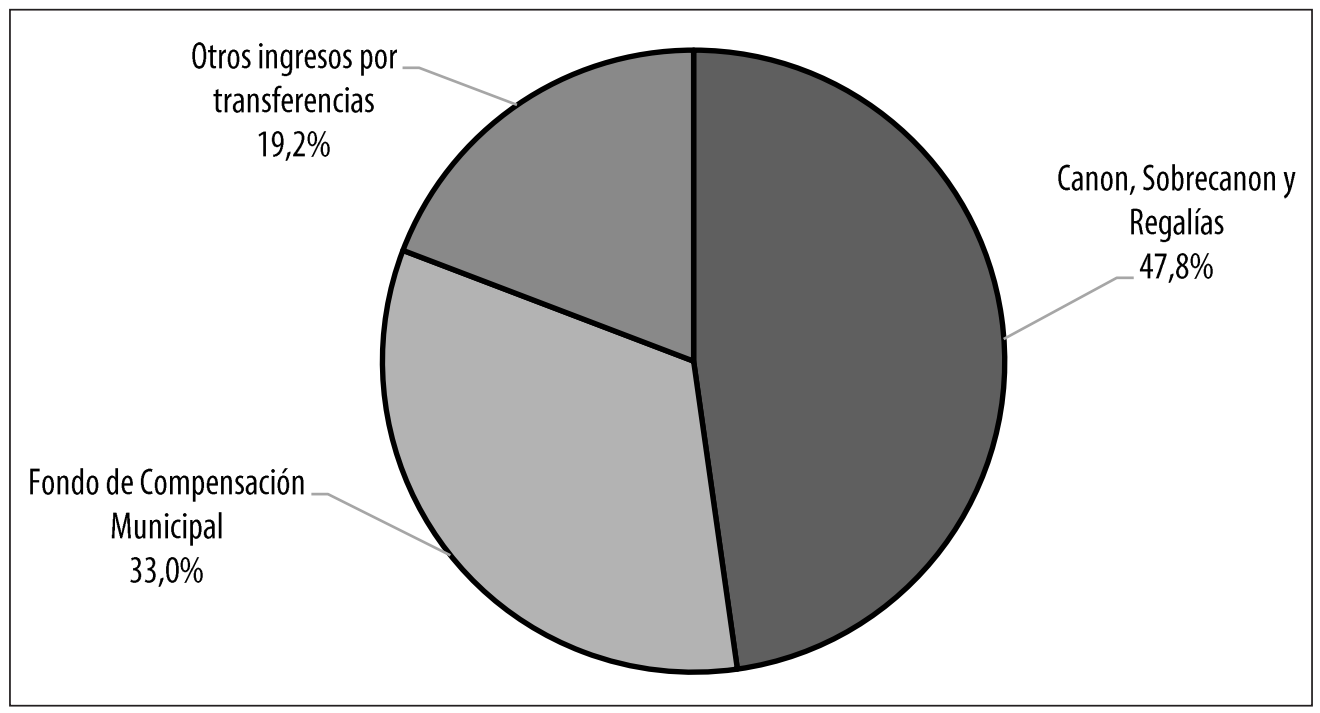

Fuente: Elaboración del autor a partir de la información de RENAMU-INEI (2014)

Por el lado del gasto, este se divide en gastos corrientes, de capital y servicio de la Deuda. La mayor parte de este se sustenta en el gasto de capital (58\% para el 2014), el cual se divide en la ejecución en activos financieros, no financieros, donaciones y transferencias de capital, y otros gastos de capital. Para el año 2014, el 98,5\% del total de gastos de capital estuvo representado por la adquisición de activos no financieros, cuya clasificación se muestra en el gráfico 3. 
Gráfico 3. Distribución de los activos no financieros en las municipalidades del Perú, 2014

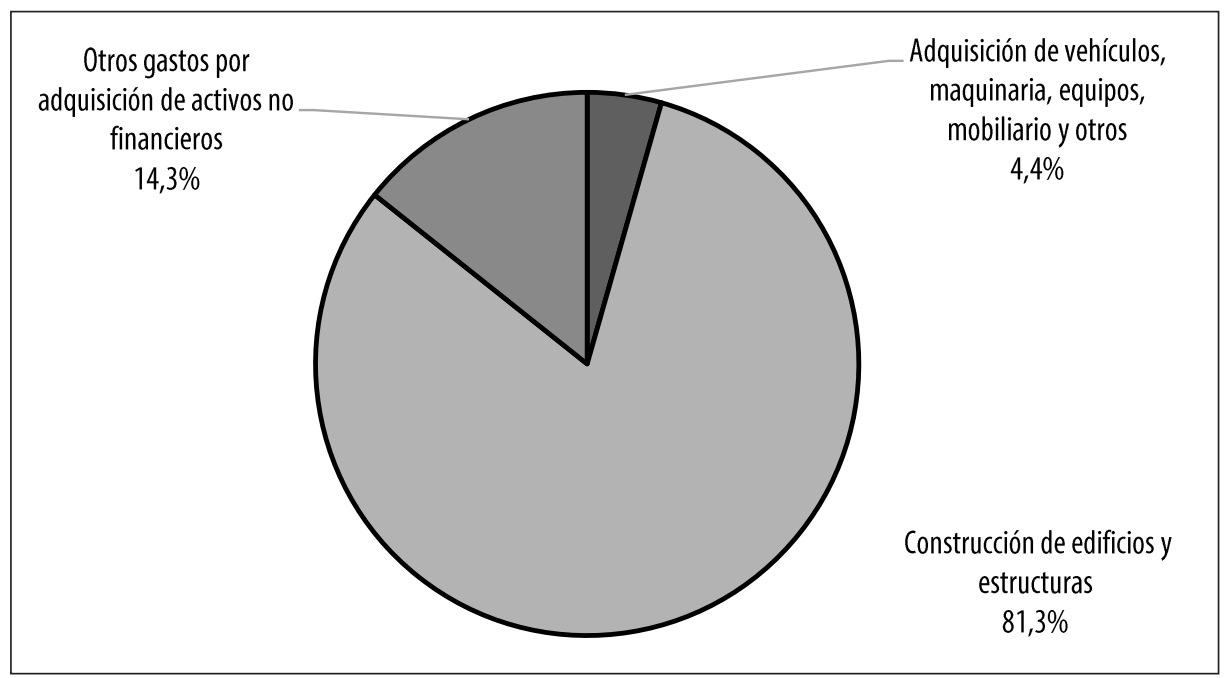

Fuente: elaboración del autor a partir de la información de RENAMU-INEI (2014)

En la clasificación de gastos por construcción de edificios y estructuras se encuentran incluidos diferentes rubros de gasto de capital municipal relacionados con el marco legal de la ejecución del canon, sobrecanon y regalías. Son nueve rubros: infraestructura vial, infraestructura agrícola, infraestructura eléctrica, sistema de agua y saneamiento, instalaciones sociales y culturales, instalaciones médicas, instalaciones educativas, plazuelas, parques y jardines, y otros gastos.

\section{ANÁLISIS DE DATOS Y RESULTADOS}

La base de datos utilizada para analizar los efectos de las variables fue obtenida a partir del último RENAMU, publicado por el INE en 2014³. Dicha base contiene información acerca de los ingresos y gastos municipales ejecutados durante el año 2014, con una cantidad total de 1838 observaciones. Dada la diversidad de los datos en cuanto al nivel de transferencias por recursos naturales, se estableció una clasificación sobre la cantidad de transferencias per cápita que los municipios reciben (cantidad de transferencia por cada habitante de la región) en referencia al trabajo de López (2011), quien realizó una tipología municipal en México respecto al tamaño de los municipios y las características rurales.

Dado esto, se realizó una clasificación en tres grupos: municipios en regiones con (1) altas, (2) medias y (3) bajas cantidades de transferencias per cápita proveniente de los recursos naturales. Se usó el promedio de transferencia per- cápita nacional,

\footnotetext{
La base de datos utilizada en este artículo estará disponible a cualquier investigador que desee solicitarla al correo: luissanchez@lamolina.edu.pe.
} 
como un valor medio donde cantidades de transferencias por encima de este se catalogaron como altas, y por debajo se consideraron como bajas (ver tabla 1).

Tabla 1. Clasificación de municipios por regiones del Perú, según la cantidad de transferencias per cápita proveniente de recursos naturales

\begin{tabular}{ll}
\hline Calificación & \multicolumn{1}{c}{ Justificación } \\
\hline Alta & $\begin{array}{l}\text { Municipios con transferencia per cápita por encima de las } 3 \text { posiciones con } \\
\text { calificación Media. }\end{array}$ \\
Media & $\begin{array}{l}\text { Municipios con transferencia per cápita alrededor del promedio total nacional } \\
(+-3 \text { posiciones })\end{array}$ \\
Baja & $\begin{array}{l}\text { Municipios con transferencia per cápita debajo de las } 3 \text { posiciones con } \\
\text { calificación Media. }\end{array}$ \\
\hline
\end{tabular}

Fuente: elaboración propia

Una vez realizada esta clasificación, se especificó un modelo econométrico del gasto de capital para cada grupo de análisis. Se tomó como referencia el modelo aplicado por Neyra y Baldárrago (2005), quienes estimaron elasticidades del gasto de capital respecto a los ingresos corrientes y las transferencias del FONCOMUN para hallar el efecto de pereza fiscal (flypaper) en las municipalidades de la región Arequipa de Perú. El modelo incluyó las variables de forma per cápita para poder homologar el análisis entre los distintos municipios y se estimó en niveles:

$$
g i p_{i}=\alpha+\beta t r_{i}+\delta f c m p_{i}+\gamma i c p_{i}+\varepsilon_{i}
$$

Dónde:

gip : $\quad$ Gasto de capital per cápita.

$\alpha$ : $\quad$ Término Independiente.

$\beta$ : $\quad$ Coeficiente de variación del gasto de capital per cápita dada la variación de la transferencia per cápita.

$t_{i}$ : $\quad$ Transferencia por recurso natural per cápita.

$\delta$ : $\quad$ Coeficiente de variación del gasto de capital per cápita dada la variación del FONCOMUN per cápita.

fcmp : $\quad$ FONCOMUN per cápita.

ү: $\quad$ Coeficiente de variación del gasto de capital per cápita dada la variación de los ingresos corrientes per cápita. 
icp $p_{i}$ Ingresos corrientes per cápita.

$\varepsilon_{i}: \quad$ Término de error del modelo.

A través de este modelo se pudo capturar el efecto de las transferencias condicionadas y no condicionadas sobre el gasto de capital. El modelo fue estimado mediante el método de mínimos cuadrados ordinarios con un número de observaciones que representó una muestra asintótica. Dada la heterogeneidad de la variable ingresos corrientes (icp), se realizó un análisis preliminar de dispersión para evitar una regresión errónea, llevándose a cabo las regresiones con aquellos municipios cuyos ingresos corrientes per-cápita fueron menores a USD 66,6. Luego de la inspección preliminar de datos se realizó la estimación econométrica con un universo de 1372 observaciones (ver anexo estadístico).

Por último, el destino del gasto se analizó a través de la información desagregada en los nueve rubros de gasto municipal que incluye el RENAMU 2014. Los rubros fueron:

- Instalaciones educativas

- Instalaciones médicas

- Instalaciones sociales y culturales

- Sistema de agua y saneamiento

- Infraestructura agrícola

- Infraestructura eléctrica

- Infraestructura vial

- Plazuelas, parques y jardines

- Otros gastos por construcción de edificios y estructuras

Cada rubro se define como aquellos gastos por el inicio, continuación y conclusión de las instalaciones respectivas que incluyen los costos de construcción por contrata y administración directa de personal, bienes, servicios y otros gastos no contemplados en las partidas anteriores, no incluyendo el equipamiento.

\subsection{Clasificación de los municipios en regiones por transferencias per cápita}

Los resultados del análisis per-cápita de las transferencias provenientes de recursos naturales mostraron que a cada habitante del Perú le corresponde USD 60,4. Sin 
embargo, en casi la mitad de las regiones, la cantidad per-cápita es menos de 20 USD. De esta manera, para el año fiscal 2014 se tiene 12 regiones con transferencias per-cápita bajas; 6 regiones con transferencias per-cápita medias y 7 regiones con transferencias per-cápita altas (ver gráfico 4).

Gráfico 4. Nivel de transferencias per cápita provenientes de los recursos naturales por regiones (en USD), año fiscal 2014

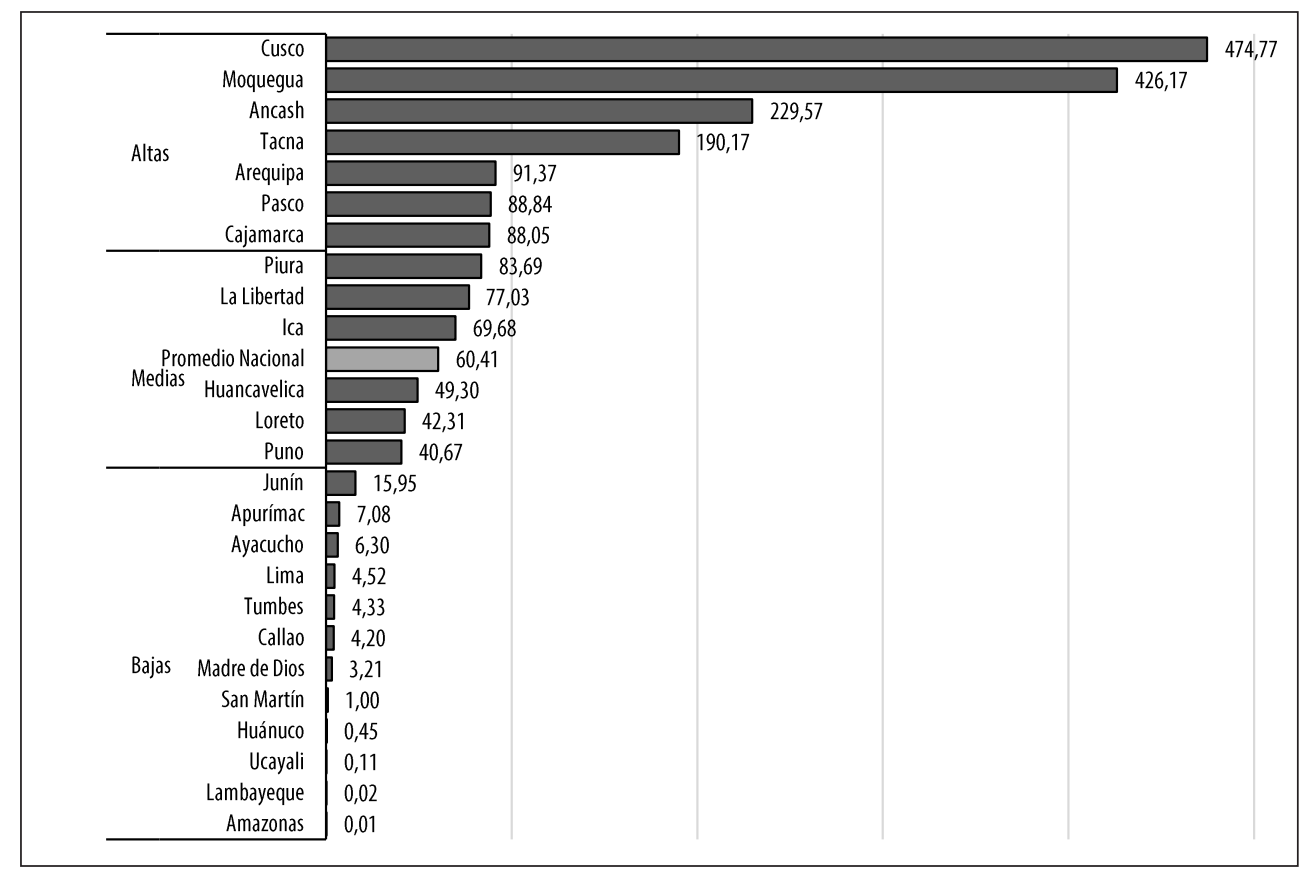

Fuente: elaboración del autor a partir de la información de RENAMU-INEI (2014)

Las regiones que alcanzaron transferencias per-cápita altas se encuentran en la sierra del país, como por ejemplo Cusco (USD 474,8), Pasco (USD 88,8); y Cajamarca (USD 88,0), pero también en la costa como Moquegua (USD 426,2) y Tacna (USD 190,2), y entre costa y parte de la Cordillera de los Andes se encuentra Arequipa (USD 91,4) y Ancash (USD 229,6). En el grupo de las regiones con transferencias bajas se incluye Lima (USD 4,52), cuya ubicación se encuentra influenciada por la densidad poblacional de la región; asimismo, en este grupo se incluyen las regiones de la selva como Amazonas que recibe la más baja cantidad de transferencia de todo el Perú (USD 0,01), Ucayali (0,11 USD), San Martín (1,00 USD) y Madre de Dios (USD 3,21). En el grupo de transferencias medias, se encuentra la región más grande del Perú, en términos de extensión, correspondiente a Loreto (USD 42,31). 


\subsection{Resultados de los modelos de regresión lineal}

El modelo demostró que las transferencias por recursos naturales en los municipios con transferencias altas y bajas obtuvieron un efecto positivo mayor sobre el gasto de capital en comparación con las otras variables regresoras (ver tabla 2). Para el caso de los municipios con transferencias per-cápita medias, el FONCOMUN fue la variable que obtuvo un mayor efecto sobre el gasto de capital, relegando a la variable de transferencia por recursos naturales. En los municipios con transferencias altas y bajas el efecto indica que por cada unidad monetaria que se adicione a las transferencias por recursos naturales, el gasto de capital se incrementaría en promedio 0,85 y 0,83 unidades monetarias, respectivamente. Para el caso de los municipios con transferencias medias, el efecto sobre el gasto de capital es de 1,05. Sin embargo, para este último grupo, la regresora FONCOMUN obtuvo un mayor efecto sobre el gasto de capital que las transferencias por recursos naturales, alcanzando un efecto de 1,49 unidades monetarias (ver tabla 2).

Tabla 2. Estimación de modelos según niveles de transferencias

\begin{tabular}{|c|c|c|c|}
\hline \multirow{2}{*}{ Estimador } & \multicolumn{3}{|c|}{ Modelos con transferencias per-cápita } \\
\cline { 2 - 4 } & Altas & Medias & Bajas \\
\hline \multirow{2}{*}{$\alpha$} & 226,68 & 37,33 & 342,51 \\
& $(1,44)$ & $(0,37)$ & $(6,91)$ \\
\hline \multirow{2}{*}{$\beta$} & 0,85 & 1,05 & 0,83 \\
& $(12,9)$ & $(14,34)$ & $(6,92)$ \\
\hline \multirow{2}{*}{$\delta$} & 0,75 & 1,49 & 0,79 \\
& $(3,88)$ & $(4,00)$ & $(5,00)$ \\
\hline \multirow{2}{*}{$\Upsilon$} & 0,73 & 1,16 & $-0,38$ \\
& $(1,44)$ & $(1,32)$ & $(-0,75)$ \\
\hline Observaciones & 486 & 377 & 509 \\
\hline \multirow{2}{*}{ R- Cuadrado } & 0,602 & 0,511 & 0,216 \\
\hline
\end{tabular}

Estadístico t entre paréntesis después de los errores robustos de White

Fuente: elaboración propia

Desde el punto de vista del federalismo fiscal, en el caso del grupo de municipios que pertenecen a las regiones con transferencias per-capita altas, la transferencia condicionada (recursos naturales) respondió mejor al gasto de capital que la no condicionada (FONCOMUN). Esto demostró algo que es evidente, dada la Ley del Canon, pues este tipo de transferencia debe ejecutarse en inversión de capital. Sin embargo, lo interesante es que el FONCOMUN también tiene una respuesta considerable sobre el gasto, y en el caso de los municipios con transferencias per- 
cápita media, llama la atención que esta transferencia tiene un efecto mayor que otras regresoras.

Por último, un aspecto que llama la atención es la no significancia estadística de la variable ingresos corrientes $(p=0,05)$ en todos los dos tipos de modelos estimados, demostrando así que dicha variable no tiene un efecto sobre la variación del gasto de capital. Bajo el enfoque positivo del federalismo fiscal, este comportamiento pone de manifiesto la posible presencia del efecto anómalo flypaper en los municipios del Perú, ya que el efecto de las transferencias sobre el gasto de capital resultó mayor que el de los ingresos corrientes.

\subsection{Destino del gasto de capital}

Los resultados mostraron que la mayor parte del gasto ejecutado para el año 2014 se destinó al rubro de infraestructura vial (33\%), siguiéndole el gasto en sistema de agua y saneamiento (21,8 \%). El menor gasto en capital se destinó al rubro de instalaciones médicas (1,9\%) y a infraestructura eléctrica (1,9\%). En el gráfico 5 se muestra la distribución del gasto de capital nacional por infraestructura para el año fiscal 2014.

Gráfico 5. Distribución y rubros del gasto en construcción de edificios y estructuras, año fiscal 2014

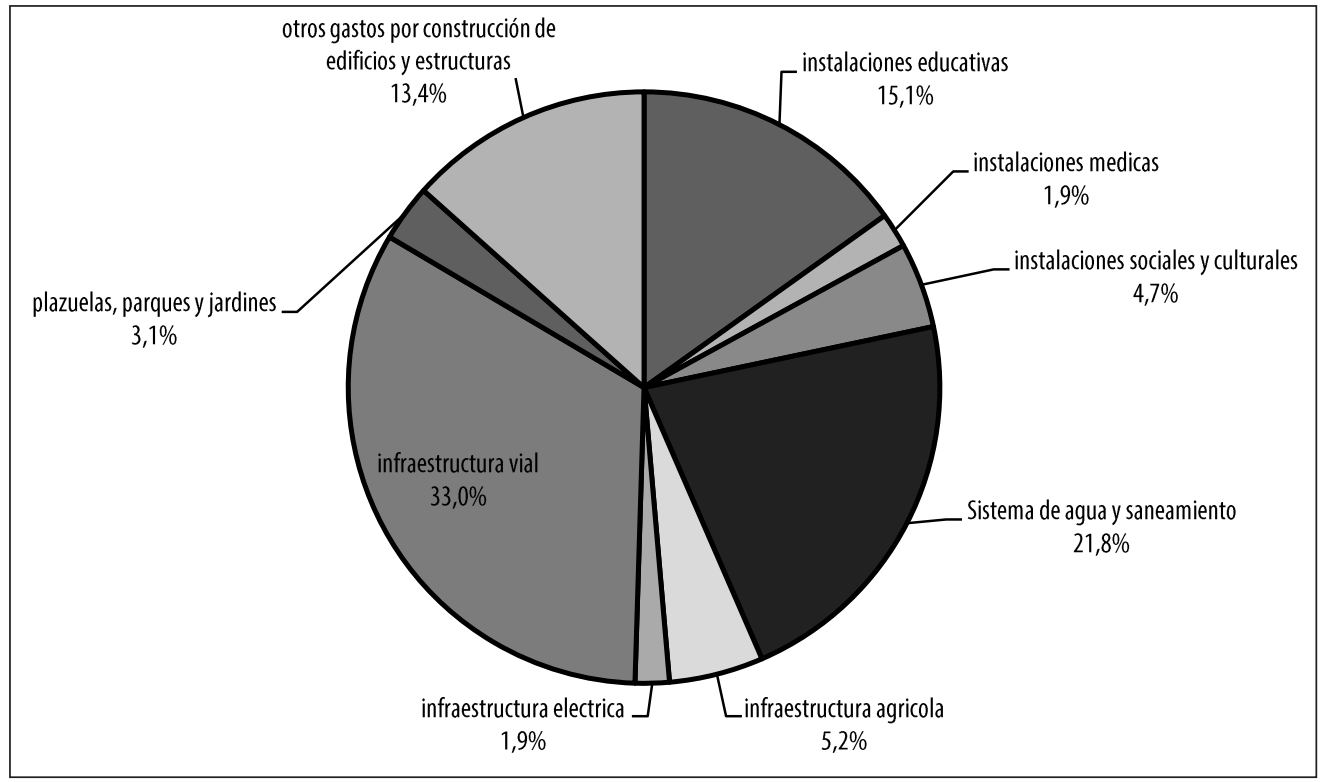

Fuente: elaboración del autor a partir de la información de RENAMU-INEI (2014)

El análisis regional indicó que los municipios de Arequipa fueron los que más 
gastaron en este rubro, dado que más del 80 \% de su gasto de capital se destinó a dicho sector. Por el contrario, los municipios en la región Amazonas fueron los que destinaron la menor cantidad a este rubro (menos del $22 \%$ de su gasto de capital total). Por otro lado, resalta el gasto de capital en infraestructura educativa de los municipios pertenecientes a las regiones de Huánuco (31,4%), Ayacucho (29,6 \%), Amazonas (24,6 \%), San Martín (22,7 \%) y Junín (22,1 \%). Asimismo, en infraestructura de salud se encuentran los municipios de las regiones Ayacucho (4,1\%), Cusco (3,9\%), Puno (3,6 \%), Pasco (3,6 \%) y Tumbes (3,1\%). En el gráfico 6 se muestra el destino del gasto de capital por regiones.

Gráfico 6. Destino del gasto de capital municipal por regiones, año fiscal 2014

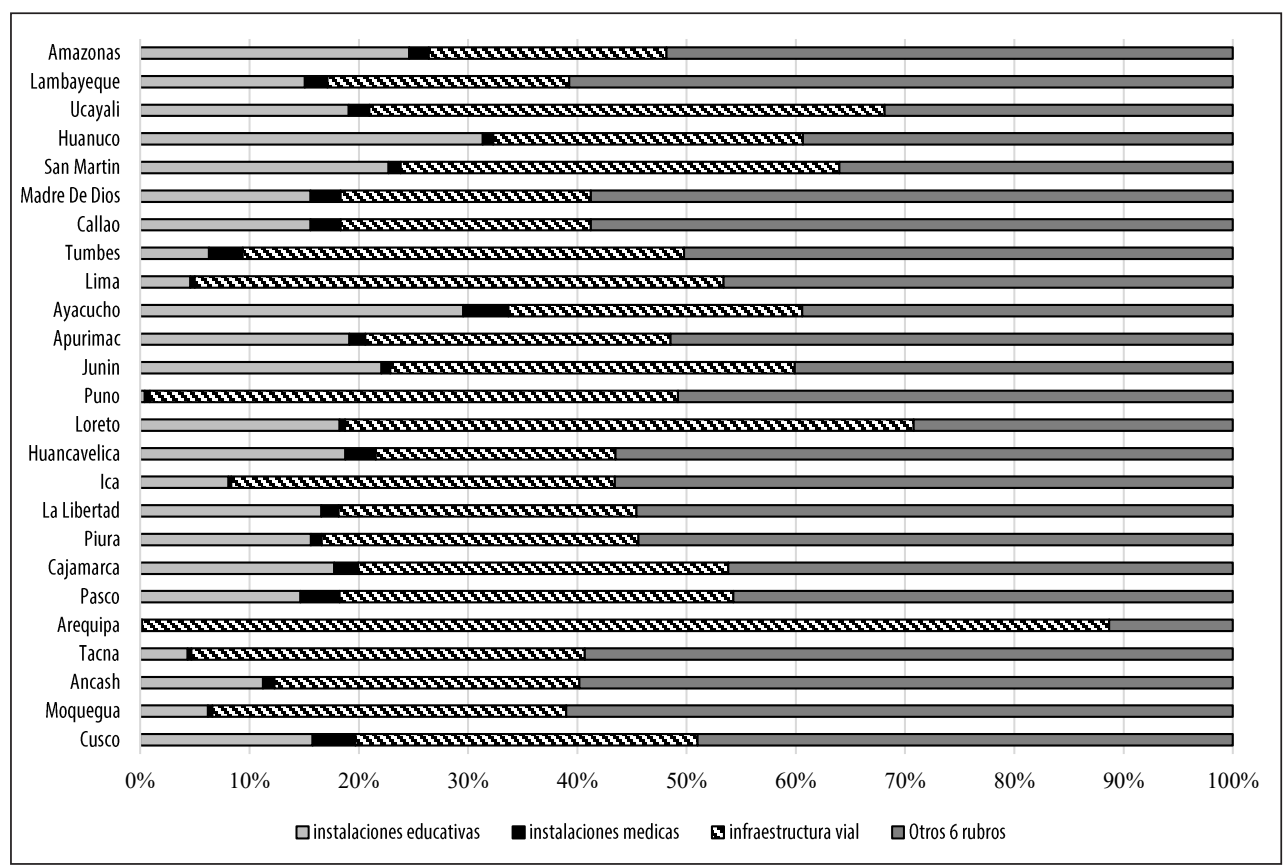

Fuente: elaboración del autor a partir de la información de RENAMU -INEI, (2014)

La región en donde los municipios han invertido más en capital humano, considerándose la suma del gasto de infraestructura en salud y educación, fue Ayacucho con un 33,7 \% de su gasto total, en donde la mayor parte tiene origen en el gasto en instalaciones educativas (29,6\%). Le sigue la región Huánuco con un 32,3% y luego las regiones de Amazonas, San Martín, Junín, Huancavelica, Ucayali, Apurímac y Cajamarca, quienes ejecutaron más del 20 \%, pero menos del 30 \% del total. Sin embargo, cabe destacar que, según la clasificación de municipios por cantidad de 
transferencias per-cápita, en el caso de transferencias altas no se evidenció un gasto significativo en educación (cerca del 18 \% en el mejor de los casos).

En salud, los municipios que pertenecen a las regiones de Cusco y Pasco sobresalen con gastos de alrededor $3 \%$. En el caso de los municipios con transferencias bajas se encuentran aquellos municipios que pertenecen a las regiones de Huánuco, Ayacucho, Amazonas, San Martín y Junín, que sobresalen en su gasto en educación con más del $20 \%$ del total ejecutado, por lo que estas regiones fueron las que más invirtieron en dicho rubro para el año 2014. El gasto en salud de la región Ayacucho es el más sobresaliente de todo el Perú, con una ejecución del 4,1 \%.

Respecto a un aporte general en educación y salud, los municipios con transferencias altas no representan aportes más allá del $20 \%$. En el gráfico 7 se muestra en orden descendente el porcentaje de gasto de capital ejecutado en el rubro de capital humano (instalaciones educativas y médicas) por regiones. En este se puede observar que los primeros puestos los ocupan aquellas regiones que pertenecen al grupo de las regiones con transferencias per-cápita por recursos naturales bajas.

Gráfico 7. Porcentaje de gasto de capital humano por regiones, año fiscal 2014

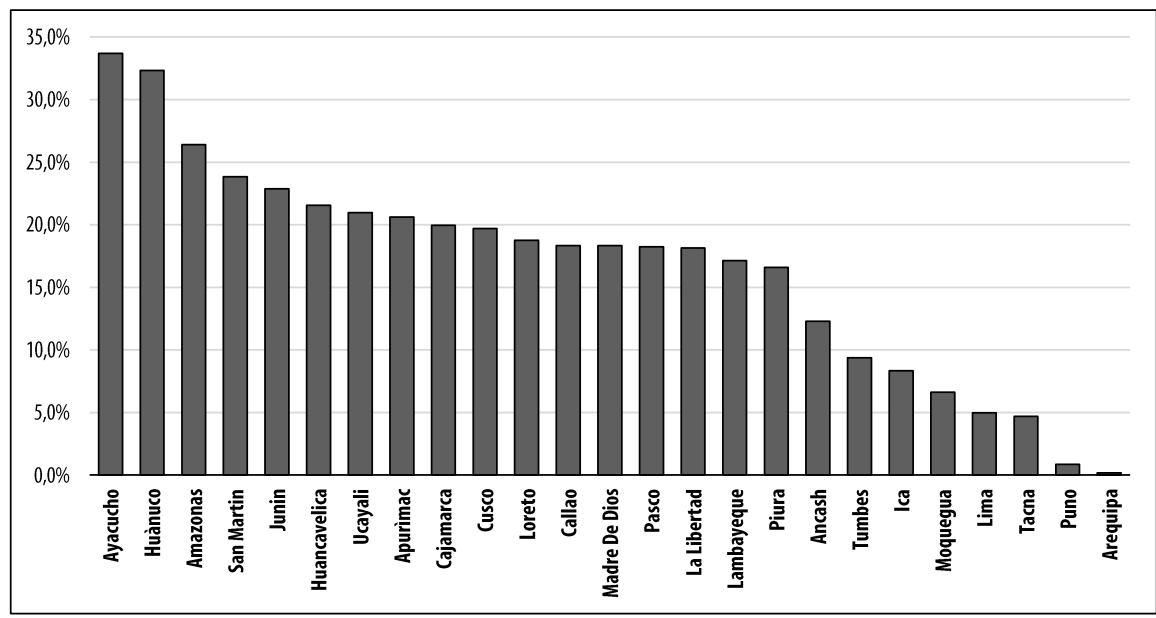

Fuente: elaboración del autor a partir de la información de RENAMU-INEI (2014)

\section{CONCLUSIONES FINALES}

El trabajo evidencia la alta dependencia de las transferencias por recursos naturales en la ejecución del gasto municipal. Sin embargo, también se demostró que el efecto es distinto por grupos de municipios, pues a mayor cantidad transferida se 
experimentó mayor sensibilidad al gasto; al parecer las transferencias por recursos naturales son vistas por los gobernantes locales solo como una transferencia de dinero, sin importar la procedencia y el costo de oportunidad que este representa, comprobándose lo dicho por el enfoque positivo del federalismo fiscal en donde el gasto público municipal es representado como una ilusión fiscal. Esta idea se refuerza más cuando los resultados del análisis de los tipos de gastos de capital tienen correspondencia al trabajo de Neira (2007), pues los resultados de la presenta investigación mostraron que los municipios en aquellas regiones en donde las transferencias por recursos naturales per-cápita resultaron bajas fueron los que realizaron un mayor gasto en salud y educación, concluyendo que no se requiere de cantidades significativas de rentas por recursos naturales para ejecutar un gasto público importante en capital humano.

Por otro lado, el hecho de que no haya evidencia estadística de que el gasto de capital sea sensible a los ingresos corrientes indicaría que los municipios del Perú carecen de recursos financieros para cumplir su función en el proceso de descentralización, es decir, no pueden cumplir con la función de asignación de forma eficiente debido a que los gastos más relevantes que ejecutan no los realizan con recursos propios sino con transferencias gubernamentales. Este efecto anómalo se observa en los tres grupos de municipios, en donde la transferencia no condicionada (FONCOMUN) sí obtuvo significancia estadística, pudiéndose evidenciar una pereza fiscal por parte de todos los municipios del Perú.

Cabe precisar que la base de datos del RENAMU, en su versión 2014, tiene información completa sobre la desagregación del gasto de capital en los nueve rubros mencionados y la clasificación de la transferencia según el tipo de recurso natural explotado; sin embargo, en sus versiones anteriores, estas clasificación no existe, razón por la cual el presente trabajo toma como punto de partida el RENAMU 2014. Asimismo, este trabajo debe servir como una investigación inicial que permita conocer a detalle el comportamiento de los municipios en Perú ante las rentas procedentes de recursos naturales, y con base en los resultados empíricos criticar desde el federalismo fiscal si dicho comportamiento se adecua a los enfoques positivos y normativos de esta teoría de la economía pública, y al final proveer la aplicación de políticas correctivas para alcanzar el tan ansiado desarrollo sostenible. 


\section{BIBLIOGRAFÍA}

Barro, Robert (1990). Government spending in a simple model of endogeneous growth. En: Journal of Political Economics. Vol. 98, No. 5, p. 103-125.

Beuren y Rodrigues (2014). Relación entre composición del gasto público y crecimiento económico de los países de América Latina. En: Invenio, Vol. 17, № 32, p. 65-87.

CRP - Congreso de la República del Perú- (2001). Ley No 27630, Ley que modifica el Artículo No 89 del Decreto Legislativo No 776 Ley de Tributación Municipal, 49p.

CRP -Congreso de la República del Perú- (2002). Ley № 27783, Ley de Descentralización, 22p.

CRP - Congreso de la República del Perú- (2003). Ley No 28067, Ley que modifica ciertos artículos de la Ley $\mathrm{N}^{\circ} 27506,4 \mathrm{p}$.

CRP -Congreso de la República del Perú- (2001). Ley 27506, Ley del Canon, 8p.

De la Fuente, Ángel (2003). Capital Humano y Crecimiento en la Economía del Conocimiento. Instituto de Análisis Económico: Madrid, España, 45p.

Devarajan, Swaroop y Zou (1996). The composition of public expenditure and economic growth. En: Journal of Monetary Economics. Vol, 37, No. 2, p. 313-344.

Giménez, Gregorio (2005). La dotación de capital humano de América Latina y el Caribe. En: Revista CEPAL, No. 86, p. 103-122.

Glaeser, E.; Scheinkman, J. y Shleifer, A. (1995). Economic growth in a cross-section of cities. NBER: Working Paper No. 5013, 35p.

Gregoriou y Ghosh (2009). The impact of government expenditure on growth: empirical evidence from a heterogeneous panel. En: Bulletin of Economic Research. Vol. 61, №. 1, p. 95-102.

Gylfason, Thorvaldur y Zoega, Gylfi (2001). Natural resources, education and economic development. En: European Economics Review, Vol. 45, mayo, p. 847-849.

Hines, James y Thaler, Richard (1995). Anomalies: The Flypaper Effect. En: The Journal of Economic Perspectives, Vol. 9, No. 4, enero, p. 217-226.

Kneller, Bleaney y Gemmell (1990). Fiscal policy and growth: evidence from OECD countries. En: Journal of Public Economics, Vol. 74, No. 2, p. 171-190.

López, Mauricio. (2011). Finanzas Municipales en México: En la búsqueda de un Eficiente Comportamiento de los Egresos. Centro de Investigación y Docencia Económica: Distrito Federal, México, 34p.

MEF -Ministerio de Economía y Finanzas - (2016). Glosario presupuesto público. Ministerio de Economía y Finanzas, Perú.

Neira, Isabel. (2007). Capital Humano y Desarrollo Económico Mundial: Modelos Econométricos y Perspectivas. En: Estudios Económicos de Desarrollo Internacional, Vol. 7, No. 2, junio-diciembre, p. $\overline{54-80 . ~}$

Neyra, Gonzalo y Baldárrago, Enrique (2005). Una aproximación a la conducta fiscal de los gobiernos municipales de Arequipa. Universidad San Agustín - Consorcio de Investigación Económica y Social, 52p. 
Parodi, Carlos (2005). En Economía de las políticas sociales. CIUP: Lima, Perú, 366p.

Piffano, Horacio (2005). En Las transferencias intergubernamentales, el esfuerzo fiscal y el nivel de actividad. UNLP, PrEbi, SeDiCL: La Plata, Argentina, 256p.

Romer, Paul (1994). The Origins of Endogenous Growth. En: The Journal of Economic Perspectives, Vol. 8, No, 1, febrero-mayo, p. 3-22.

Tello, Mario (2015). Recursos naturales, diversificación y crecimiento regional del Perú. En: Revista Economía, Pontificia Universidad Católica del Perú (PUCP), Vol. 38, No. 75, enero-junio, p. $41-100$.

Trujillo, Lucía (2008). Transferencias gubernamentales y gasto local. Repensando la descentralización fiscal desde una revisión de la literatura. En: Gestión y Política Pública, Vol. 17, No. 2, agosto - diciembre, p. 456-481.

Wiesner, Eduardo (1994). Fiscal Decentralization and Social Spending in Latin America: The Search for Efficiency and Equity. Washington, World Bank, Working Paper Series, No. 199, 34p. 


\section{ANEXOS}

\section{A) ESTADÍSTICOS DESCRIPTIVOS}

Grupo de observaciones con transferencias per-cápita altas

\begin{tabular}{|r|rrrrr|}
\hline Variable & Obs & Mean & Std. Dev. & Min & Max \\
\hline gip & 578 & 1399.225 & 2212.407 & 88.61387 & 26484.38 \\
$\operatorname{tr}$ & 578 & 898.9932 & 1445.751 & 75.83025 & 14939.24 \\
$\operatorname{Re}$ & 578 & 19.07028 & 45.0104 & .3566651 & 734.3693 \\
NRe & 578 & 879.923 & 1446.332 & 74.54532 & 14930.84 \\
fcmp & 578 & 265.076 & 158.1984 & 43.9816 & 1851.852 \\
\hline icp & 578 & 140.8278 & 286.6467 & .385171 & 2964.98 \\
\hline
\end{tabular}

Fuente: elaboración del autor a partir de la información de RENAMU-INEI (2014).

Grupo de observaciones con transferencias per-cápita medias

\begin{tabular}{|r|rrrrr|}
\hline Variable & Obs & Mean & Std. Dev. & Min & Max \\
\hline gip & 400 & 901.6169 & 933.0305 & 45.39819 & 8025.729 \\
tr & 400 & 381.3917 & 592.633 & 23.85658 & 5853.799 \\
Re & 400 & 38.5396 & 96.49367 & $1.21 \mathrm{e}-06$ & 1550.224 \\
NRe & 400 & 342.8521 & 592.9299 & 22.96805 & 5852.381 \\
fcmp & 400 & 257.4496 & 142.4184 & 45.84784 & 1204.439 \\
\hline icp & 400 & 70.25124 & 128.4859 & & 2038.315 \\
\hline
\end{tabular}

Fuente: elaboración del autor a partir de la información de RENAMU-INEI (2014).

Grupo de observaciones con transferencias per-cápita bajas

\begin{tabular}{|r|rrrrr|}
\hline Variable & Obs & Mean & Std. Dev. & Min & Max \\
\hline gip & 586 & 689.7003 & 749.8733 & 10.727 & 5602.627 \\
tr & 586 & 162.1303 & 355.2287 & .0001442 & 3899.397 \\
Re & 586 & 26.66224 & 67.97566 & $4.13 e-06$ & 863.4108 \\
NRe & 586 & 135.4681 & 340.11 & 0 & 3899.392 \\
fcmp & 586 & 280.0706 & 212.875 & 14.05283 & 1612.903 \\
\hline icp & 586 & 122.3496 & 304.1628 & 0 & 3935.14 \\
\hline
\end{tabular}

Fuente: elaboración del autor a partir de la información de RENAMU-INEI (2014) 


\section{B) GRÁFICOS DE DISPERSIÓN}

Grupo de observaciones con transferencias per-cápita altas

Variable gastos vs. variable ingresos corrientes (578 observaciones)

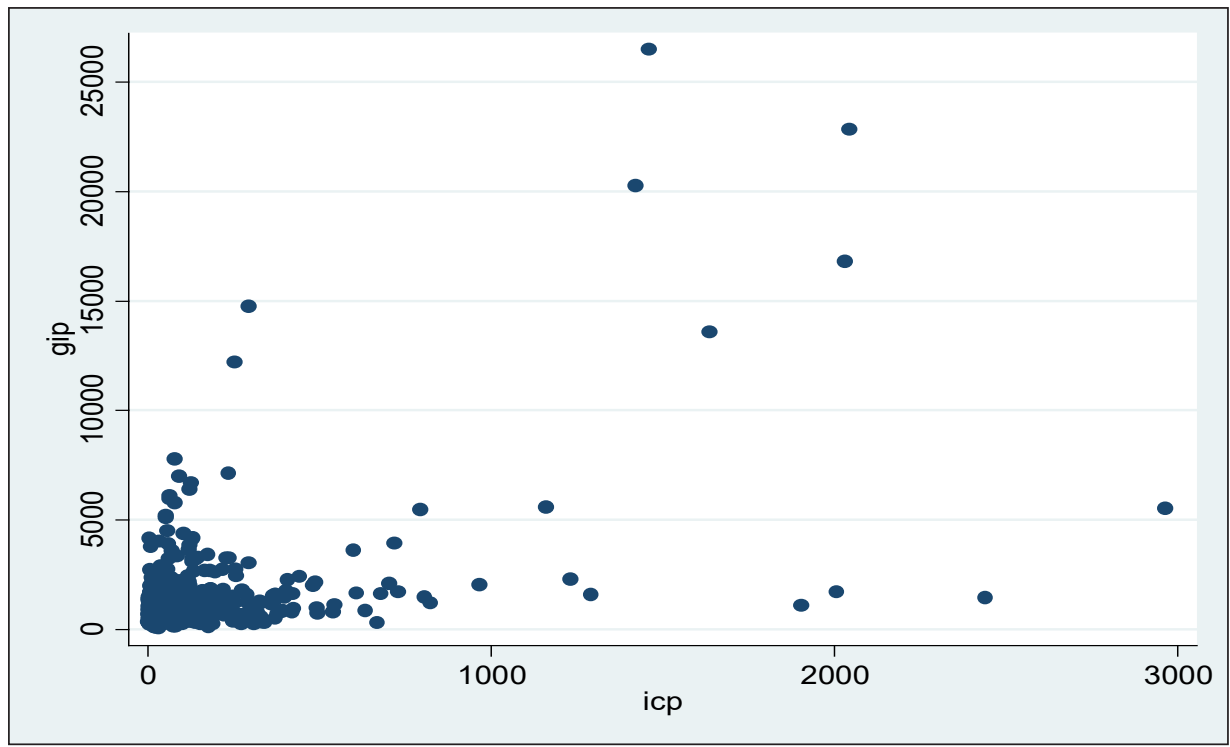

Fuente: Elaboración del autor a partir de la información de RENAMU-INEI (2014)

Variable gastos vs. variable ingresos corrientes (486 observaciones)

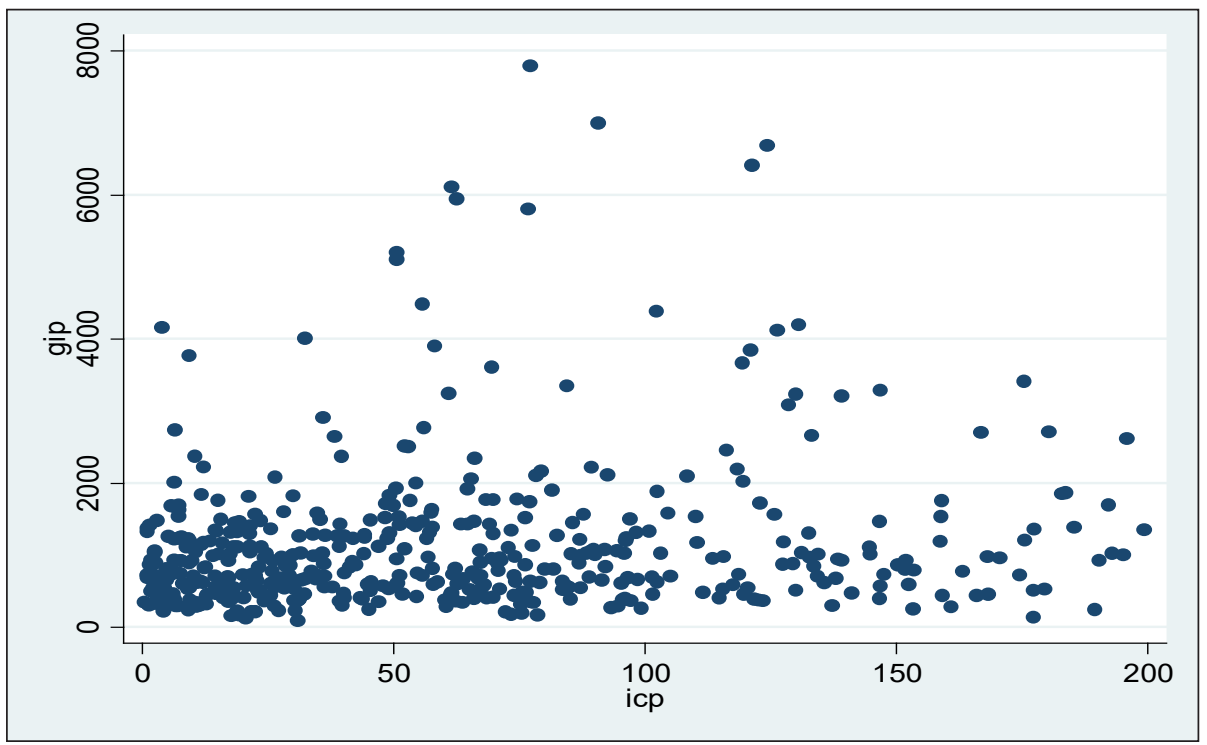

Fuente: Elaboración del autor a partir de la información de RENAMU-INEI (2014) 
Grupo de observaciones con transferencias per-cápita medias

Variable gastos vs. variable ingresos corrientes (400 observaciones)

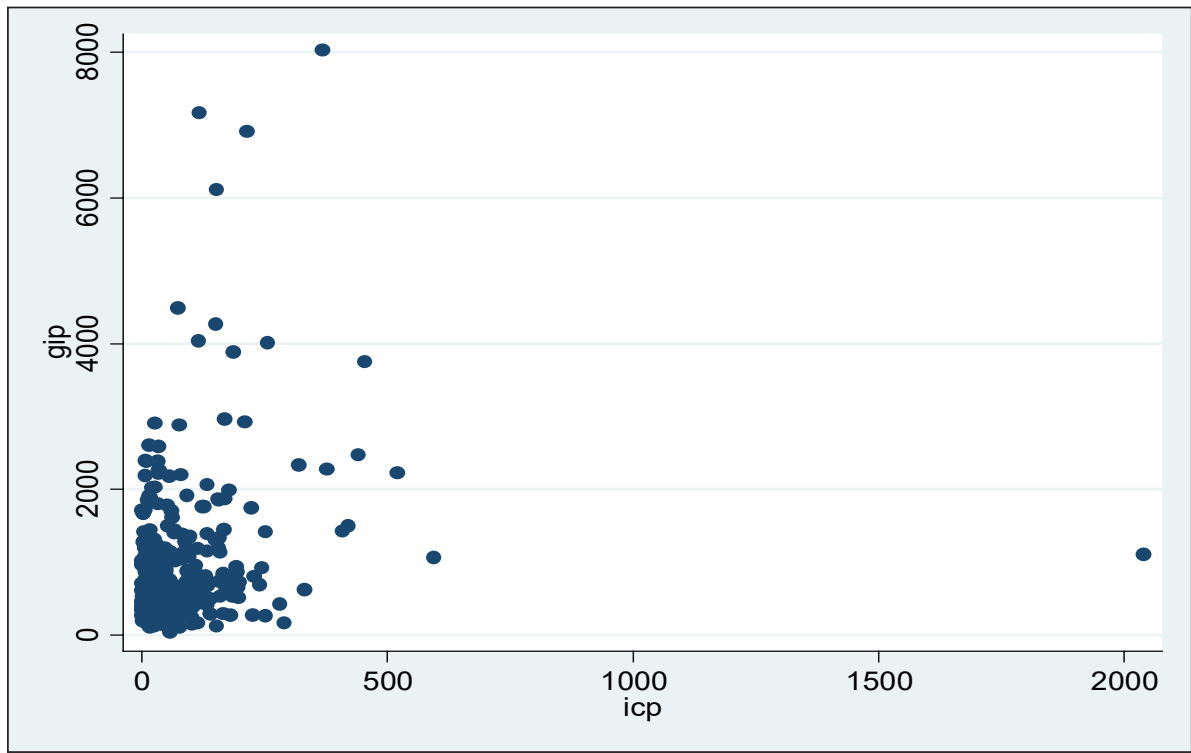

Fuente: Elaboración del autor a partir de la información de RENAMU-INEI (2014)

Variable gastos vs. variable ingresos corrientes (377 observaciones)

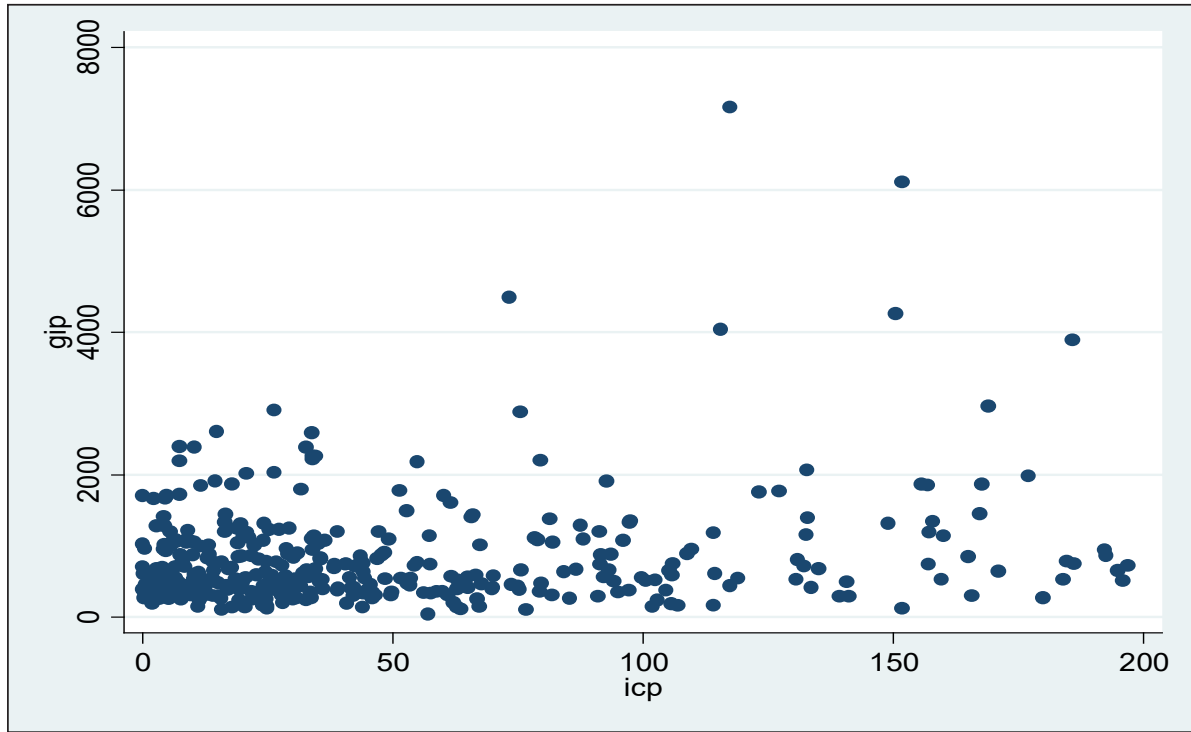

Fuente: Elaboración del autor a partir de la información de RENAMU-INEI (2014) 
Grupo de observaciones con transferencias per-cápita bajas

Variable gastos vs. variable ingresos corrientes (586 observaciones)

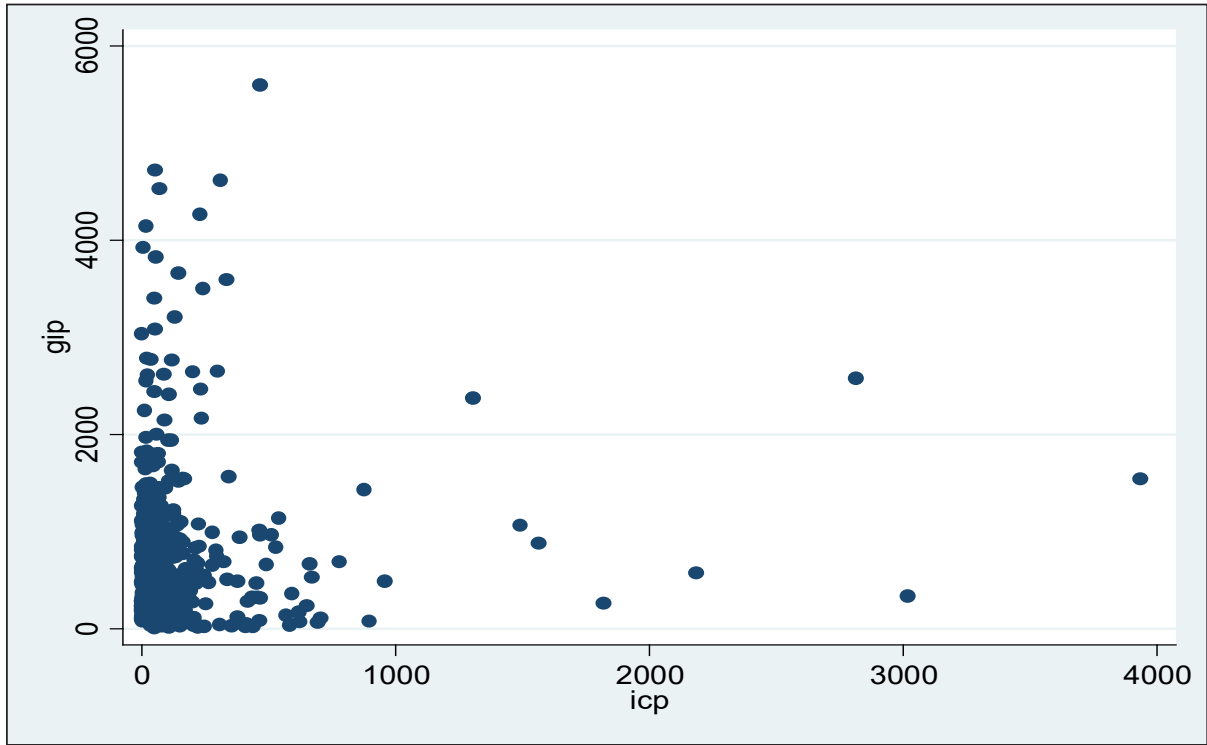

Fuente: elaboración del autor a partir de la información de RENAMU-INEI (2014)

Variable gastos vs. variable ingresos corrientes (509 observaciones)

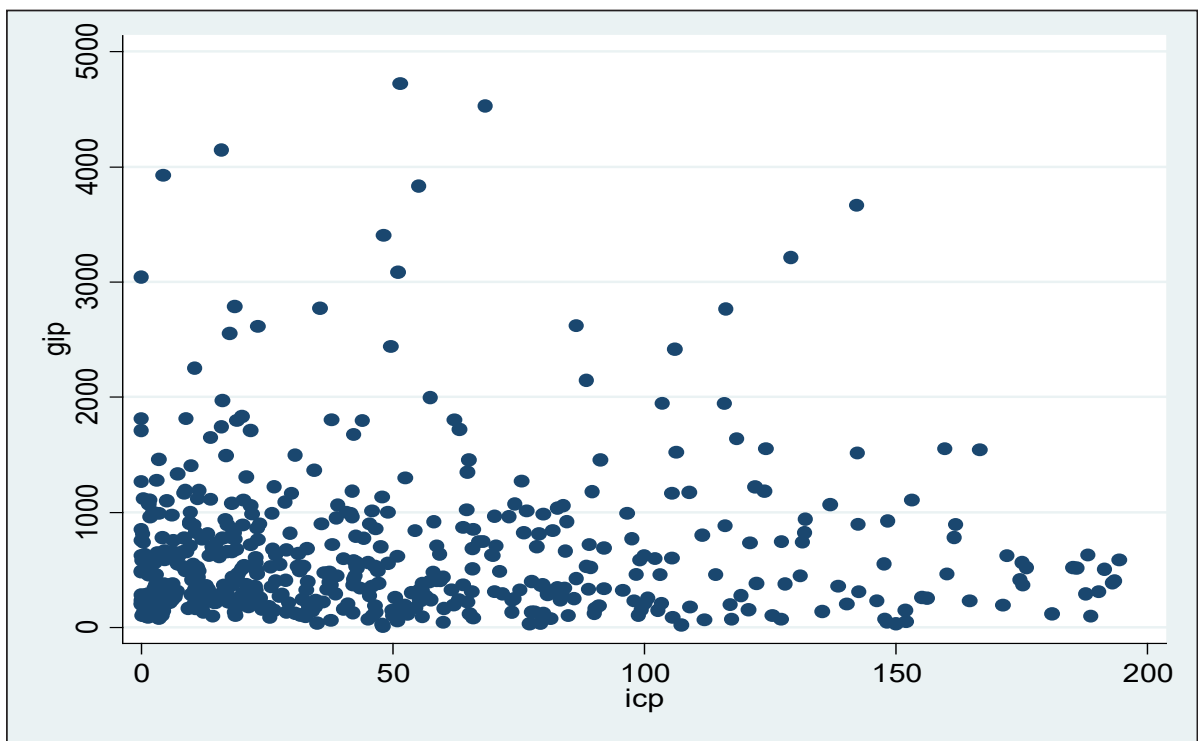

Fuente: elaboración del autor a partir de la información de RENAMU-INEI (2014) 
Transferencias gubernamentales e inversión en capital en municipios peruanos: el caso de las rentas por recursos naturales

\section{C) TEST DE HETEROCEDASTICIDAD}

Grupo de observaciones con transferencias per-cápita altas

\begin{tabular}{|c|c|c|c|c|c|}
\hline Source & SS & $d f$ & MS & \multirow{2}{*}{$\begin{array}{l}\text { Number of obs } \\
\mathrm{F}(3,482) \\
\text { Prob }>\mathrm{F}\end{array}$} & \multirow{2}{*}{$\begin{array}{r}486 \\
243.60 \\
0.0000\end{array}$} \\
\hline Model & \multicolumn{2}{|l|}{316425667} & 105475222 & & \\
\hline Residual & 208701881 & 482 & 432991.454 & R-squared & 0.6026 \\
\hline Total & 525127548 & 485 & 1082737.21 & $\begin{array}{l}\text { Adj R-squared } \\
\text { Root MSE }\end{array}$ & 658.02 \\
\hline gip & Coef. & Std. Err. & t & [95\% Conf & . Interval] \\
\hline $\operatorname{tr}$ & .8508401 & .0324403 & 26.23 & .7870982 & .914582 \\
\hline fcmp & .7585562 & .2326242 & 3.26 & .3014734 & 1.215639 \\
\hline icp & .7356295 & .6180828 & 1.19 & -.47884 & 1.950099 \\
\hline _cons & 226.689 & 81.43458 & 2.78 & 66.67836 & 386.6996 \\
\hline \multicolumn{6}{|c|}{ - estat hettest } \\
\hline \multicolumn{6}{|c|}{$\begin{array}{l}\text { Breusch-Pagan / Cook-Weisberg test for heteroskedasticity } \\
\text { Ho: Constant variance } \\
\text { Variables: fitted values of gip }\end{array}$} \\
\hline \multicolumn{2}{|c|}{$\operatorname{chi2}(1)$} & 52.62 & & & \\
\hline Prob > chi2 & chi2 & .0000 & & & \\
\hline
\end{tabular}

Fuente: elaboración del autor a partir de la información de RENAMU-INEI (2014) 
Luis Sánchez Alcalde

\section{Grupo de observaciones con transferencias per-cápita medias}

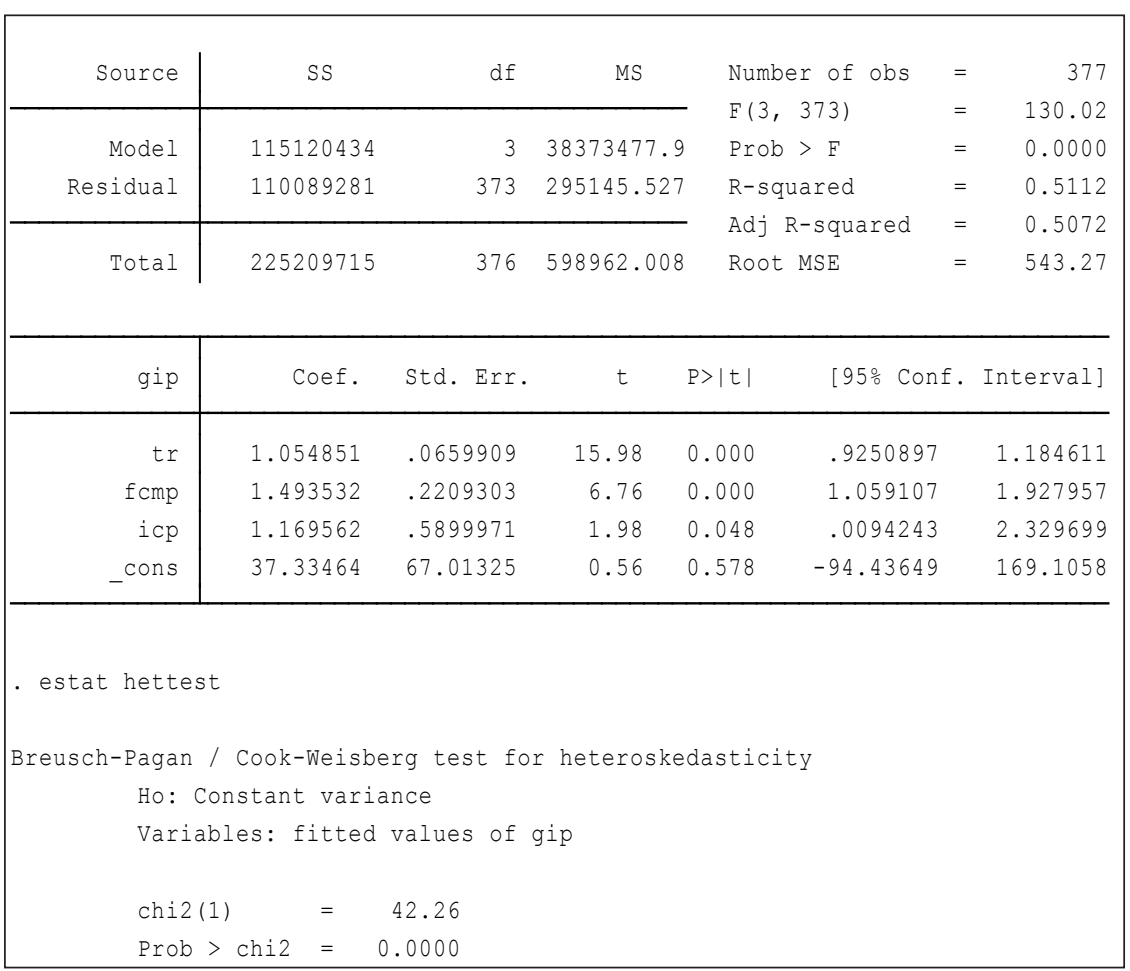

Fuente: elaboración del autor a partir de la información de RENAMU-INEI (2014) 
Transferencias gubernamentales e inversión en capital en municipios peruanos: el caso de las rentas por recursos naturales

\section{Grupo de observaciones con transferencias per-cápita bajas}

\begin{tabular}{|c|c|c|c|c|c|c|}
\hline Source & SS & $d f$ & MS & \multirow{2}{*}{\multicolumn{2}{|c|}{$\begin{array}{l}\text { Number of obs } \\
\mathrm{F}(3,505) \\
\text { Prob }>\mathrm{F}\end{array}$}} & $\begin{array}{r}509 \\
46.48\end{array}$ \\
\hline Model & 49304363.8 & 3 & 16434787.9 & & & 0.0000 \\
\hline Residual & 178573385 & 505 & 353610.663 & \multicolumn{2}{|c|}{ R-squared } & 0.2164 \\
\hline Total & 227877749 & 508 & 448578.245 & \multicolumn{2}{|c|}{$\begin{array}{l}\text { Adj R-squared } \\
\text { Root MSE }\end{array}$} & $\begin{array}{l}0.2117 \\
594.65\end{array}$ \\
\hline gip & Coef. & Std. Err. & t & $p>|t|$ & [95\% Conf & Interval] \\
\hline $\operatorname{tr}$ & .8338992 & .0913132 & 9.13 & 0.000 & .6544987 & 1.0133 \\
\hline fcmp & .7952689 & .1325601 & 6.00 & 0.000 & .5348317 & 1.055706 \\
\hline icp & -.3898677 & .5554807 & -0.70 & 0.483 & -1.481205 & .7014701 \\
\hline _cons & 342.5156 & 54.38614 & 6.30 & 0.000 & 235.6647 & 449.3666 \\
\hline \multicolumn{7}{|c|}{ - estat hettest } \\
\hline \multicolumn{7}{|c|}{$\begin{array}{l}\text { Breusch-Pagan / Cook-Weisberg test for heteroskedasticity } \\
\text { Ho: Constant variance } \\
\text { Variables: fitted values of gip }\end{array}$} \\
\hline \multicolumn{2}{|c|}{$\operatorname{chi2}(1)$} & 26.63 & & & & \\
\hline Prob > chi2 & $\operatorname{chi2}=$ & .0000 & & & & \\
\hline
\end{tabular}

*** Los problemas de heterocedasticidad de corrigieron con los errores robustos de White.

Fuente: elaboración del autor a partir de la información de RENAMU-INEI (2014) 
